\title{
PARTNER COMMUNICATION AND DECISION-MAKING REGARDING SEXUAL ISSUES AMONG STUDENTS IN A SOUTH AFRICAN UNIVERSITY
}

\author{
EUNICE ALLEN SUNDAYI - EMEKA E. OBIOHA
}

\begin{abstract}
Young people are faced with the threat of high levels of HIVIAIDS and unwanted pregnancies in South Africa. Thus it is important to understand partner communication and shared reproductive decision-making processes with regard to these sexual risks. This study draws on in-depth interviews conducted with 20 black students aged 18-24 years old at the Walter Sisulu University. The study found that many young people engaged in risky sexual behavior. Differing cultural norms that created different standards for men and women discouraged partner communication and shared decision-making and seemed to significantly promote risky sex. The study suggests that men often dominated the decision-making process. In addition, partner coercion was prevalent, and negatively affected the health choices of young people. Young people were afraid to freely discuss sexual issues and their preferred course of action in order to avoid antagonizing partners who might suspect them of infidelity, lack of commitment or HIV-positive status. Moreover, the cues used to communication their sexual desires and concerns were at times misunderstood. Given the negative repercussions of sexual risks, it is important that, in addition to creating greater awareness of risks and adopting prevention strategies, health promotion interventions that go beyond raising risk awareness and incorporate the cultural, social and economic contexts in which partner communication and shared decision making occur should be encouraged.
\end{abstract}

KEYWORDS: partner communication, shared-decision making, health promotion, sexual behaviors

1 Eunice Allen Sunday (corresponding author) is lecturer at the Walter Sisulu University, Mthatha, South Africa, email: eunicenyiraneza@gmail.com; Emeka E. Obioha is Professor at the Walter Sisulu University, Mthatha, South Africa, email: emekaobioha@ gmail.com 


\section{INTRODUCTION}

In virtually every sexual relationship, communicating with a partner is an important self-protective health behavior. Through communication, one is able to learn the history of the other partner's sexual behavior and the level of risk one might be exposed to. This information will no doubt lead to safer sex practices. Conversations about sex have been found to be critical in preventing HIV and other sexually transmitted infections through the expression of sexual consent, and sexual desires and satisfaction (Faulkner et al. 2010 cited in Nu Tanga et al. 2013). Similarly, Tamaryn et al. (2013) state that in a South African setting effective communication between couples is critical for the interventions that affect sexual behavior to work (Tamaryn et al. 2012). It is particularly important among youth: the segment of the population which is highly experimental.

Young people aged 15-24 years old account for a significant proportion of the global population. In 2015 they numbered 1.2 billion, accounting for one out of every six people worldwide (United Nations NAIDS 2015). Similarly, the age group 15-24 represent 24\% of South Africa's population (UNFPA 2013), and this major demographic group faces significant risks related to sexual and reproductive health. Appropriate partner communication and shared decision making about sexual matters is likely to lessen the sexual risks that threaten a significant proportion of the world's population. The 1994 (ICPD) in Cairo clearly recognized and emphasized the importance of shared reproductive decision-making.

While we acknowledge that appropriate partner communication and shared decision making is essential, the literature about this topic is inadequate. Until relatively recently, much work with the youth of developing countries has centered on the prevention of sexual risks, rather than the promotion of sexual health. The few studies that have been conducted about the promotion of reproductive and sexual health indicate that partner communication is weak in many developing countries, and that gender-based power inequity contributes to this situation (Blanc 2001). Similarly, current studies indicate that processes such as partner communication and collaboration have been least studied in sub-Saharan Africa (Conroy 2014). For instance, Minnis et al. (2015) claims that in the few studies conducted in South Africa, low levels of sexual and relationship communication among partners have been identified. In scenarios where communication exists, women have low control over sexual decision making in relationships, including a reduced ability to negotiate condom use and make decisions about when to have sex, and that there is widespread acceptance that men may have multiple sexual partners. Minnis et al. (2015) further observed that, in spite of important legal and policy efforts adopted in South Africa to promote greater gender equality, 
gender-based power structures in relationships and intimate partner violence (IPV), whose impact on HIV risk is exacerbated by alcohol and drug use, are responsible for inadequate partner communication and a lack of gender equality. Given this background, a substantial proportion of the population - youth - are faced with the high-level threat of HIV/AIDS infections and unwanted pregnancies.

Southern Africa, the location for the current study, remains the epicenter of the global AIDS epidemic. South Africa in particular is home to the greatest number of people with HIV in the world (6.8 million), and 240,000 South Africans dying from AIDS-related illnesses (UNAIDS 2014). Statistics show that 15-24 year olds are presently the age group most susceptible to HIV, both nationally and internationally. In South Africa by the year 2011 the prevalence of HIV/AIDS among those aged 15-24 years was 17.2\% (Population Reference Bureau 2013). Moreover, Parker (2003) has observed that about half of all adults who acquire HIV in South Africa are infected before they turn 25 years of age. Parker further states that over $50 \%$ of all HIV infected young people in the same country die before their $35^{\text {th }}$ birthday. Pembrey (2006) has observed that, besides a high level of morbidity and mortality due to HIV/AIDS, HIV positive people face prejudice and discrimination in many areas of life. In addition, households suffer from AIDS-related financial hardships due to the long periods of illness caused by HIV/AIDS, including a loss of income and the cost of caring for a dying family member, which can impoverish a household. The epidemic also cripples health systems, especially in developing countries. Allocating resources to HIV/AIDS prevention and treatment diverts attention from other health concerns.

Kaufman et al. (2001) have stated that although lifetime fertility has fallen close to below replacement level, fertility rates among young people remain high in South Africa. The SADHS of 1998 demonstrated that the proportion of teenage girls who had experienced a pregnancy grew from 2.4 per cent to 35,1 per cent with each additional year of age from 15 to 19 (Swartz 2003).

Early-age pregnancy and childbearing contribute to high levels of mortality and morbidity which occur due to the reproductive health problems which harm the health of young women and deter their ability to function normally (Nugent 2005). In low-income countries about 68,000 of all pregnancy-related deaths are due to unsafe abortions, especially unwanted pregnancies. In Africa, 60\% of women who have unsafe abortions are under the age of 25. In addition, in most low-income countries children born to young mothers face poor survival prospects and a higher chance of serious illness and disability (Tinker and Ruben 2006). In numerous societies, unwanted pregnancy means the end of formal education for a girl, because the prospective mother is expected to care for the child. In South Africa, unwanted teenage pregnancies are common. 
Swartz (2003) notes that the father of a child rarely takes responsibility for its financial, emotional and practical support. Hence, childcare entirely depends on the mother, with potential support from her parents.

In spite of the above-described situation, whereby the prevalence of HIV/AIDS and unwanted pregnancy is highlighted as a cause for concern among the youth, a dearth of information exists about partner communication and shared decision making about sexual issues. Accordingly, the current study sought to determine whether partner communication occurs about sexual issues, including HIV/ AIDS and unwanted pregnancy, among young university students. Assuming that partner communication does occur between young university students, the study sought to determine what form it takes. Secondly, the study sought to establish the factors that inhibit or facilitate decision making related to the practice of safe sex among young university students. Lastly, given that young people come from cultures where predefined gender roles influence the power imbalance in sexual relationships, this study sought to determine how and why young university students coerce their sexual partners. According to Ajzen (1988), studies show that the interaction of personal, proximal and distal factors are the major influence on individual behavior.

\section{THEORETICAL FRAMEWORK}

The theory of planned behavior and gender theory guide the present study. The theory of planned behavior recognizes that persons may not be under complete (perceived) control over their behavior. Contextual and cultural factors are also major determinants (Ajzen 1988). In the present study, a young person's ability to negotiate and decide to practice safe sex to avoid unwanted pregnancy and HIV infection was significantly influenced by social factors such as partner/peer pressure and cultural norms about masculinity and femininity. Similarly, gender theory claims that the cultural endorsement of a conventional male role as more valuable strengthens the power imbalance between men and women (Lefkowitz et al. 2014). In South Africa, during colonial and apartheid regimes, participation in the migrant labor system dispossessed African men in a larger, societal sense, but ensured their domination and control over gender relations locally. Men's continuing possession of rural homes and connections perpetuated patriarchal systems of authority, which include the subordination of women. Despite laws promoting the emancipation of women, the gender power differential and its effects are still evident and strong in traditional South African settings. Thus it is not surprising that the high number of teenage pregnancies and the high level 
of gender-based violence and HIV in South Africa are outcomes of the risky behavior of some men that is acted out to protect masculinity, and of women's submissiveness that seeks to protect an ideal of femininity. Lefkowitz et al. (2014) observes that a gender power differential can lead to risky sexual behaviors and beliefs. As the 'submissive' gender, women are unable to negotiate about safer sex, since, among other factors, open partner communication about such issues is viewed as inappropriate (Lefkowitz et al. 2014).

\section{METHODS}

\section{Participants and Procedures}

Study participants consisted of a highly educated sample of young Walter Sisulu university students $(\mathrm{N}=20)$. The researcher sought and was granted permission from the university administration to conduct the study. Recruitment of potential participants was done through face-to-face contact and verbal persuasion. Prior to participation, the participants provided verbal consent for their participation at times when they were not attending lectures/tutorials/peer discussions. The researcher then administered in-depth interviews to 20 black students aged 18-24 years old: 10 females and 10 males. The average age of the sample was 21 years. Some reported to being single, while most of them were dating. The interviews were conducted in English, although participants were permitted to speak vernacular if they desired. A research assistant helped to translate responses captured in the local language into English. All the responses were recorded through note-taking and tape recording.

\section{Data Analysis}

The researchers used thematic analysis for the investigation (Braun \& Clarke 2006), starting by reading through the transcripts to gain a general sense of budding topics. To develop an initial pattern of themes, transcripts of individual respondents were read individually to determine what content emerged as interesting or important. The researcher then began the process of reading, coding, categorizing, discussing, and refining ideas. Overlapping and repetitive statements were removed 
and statements were then organized into meaningful units (e.g. communication about condom use). These meaningful units were then finally organized into meaningful themes (e.g. decision-making about condom use).

\section{DATA PRESENTATION AND ANALYSIS OF FINDINGS}

\section{Partner Communication about sexual activity modalities}

Participants stated that verbal communication makes sexual partners feel uncomfortable. At the beginning of a relationship, most young people avoid asking questions about their partner's sex life and other sex-related issues for fear of antagonizing their partner. Partners prefer to use cues to communicate, rather than talking openly about sexual desires. For instance, cues such as saying 'I miss you' and 'come to my place', kissing, touching and stripping suggest a desire to have sex. When male partners communicate, female partners are expected to understand and respond. For female partners, signaling using action is done with caution to avoid being viewed as sexually vulnerable. Below are some of the responses from both male and female respondents.

"When we kiss she goes on and on, then I know what she wants" (IDI \#6, male).

"When we are at his place, I start kissing him, taking off his clothes, touching his sensitive parts and then he knows what I want" (IDI \# 6, female)

"I could not tell him that I want to have sex. I just tell him that I miss him, I am coming to his place, and then he knows what I want" (IDI \#1, female).

Once a guy acts on it [his feelings], then you feel free to go on, but when it is a girl it feels very uncomfortable. I do not want him to say I cannot control myself" (IDI \#8, female).

Similarly, participants said that partners use cues to refuse sexual demands from their partners. When women do not honor appointments they have made or do not accept being romanced by partners then it is understood that such women do not want to have sex. In contrast, males verbally and openly refuse sexual advances by partners. According to some male respondents: "She may say, I cannot do this (romance) or she may not arrive for the appointment which you made with her. Girls just disappear" (IDI \#2, male). "I just tell her that I do not feel like making love today" (IDI \#6, male). 


\section{Decision-making modalities over sexual activity}

Most respondents stated that males dominated decisions about the timing of sexual intercourse. According to male respondents, sexual intercourse should occur as soon as one has started a relationship in order to show commitment and love. "A girl might say she is not available at the time the boy wants it (sex), or, 'why have sex at a particular time'? But for the guys the sooner they have sex, the better. If I had a girlfriend, sexual intercourse would surely be a sign of love and trust" (IDI \#2, male). Respondents stated that males blackmail their female partners by accusing them of being unfaithful and uncommitted to the relationship if they refuse to have sex. Some girls felt intimidated, and, against their will, succumbed to partners' sexual demands. In the words of some female respondents: "If I say I am not interested in sex sometime, he gets angry because he thinks I have found a new boyfriend" (IDI \#5, female). "If I said no to sex he would think that I didn't love him and this would hurt me and I would be forced to have sex with him" (IDI \# 1, female).

When asked about who initiated sexual activity, all the males and $70 \%$ of female respondents indicated that male partners were responsible for initiating sex. They said that since it is the men who initiate the relationships, they are also therefore most likely to initiate sex. Girlfriends are expected to listen and obey. One of the female respondents opined: "Normally my boyfriend makes the decision for us to have sex. He would ask me to go to his home and I go to his home. He does not say anything, but you know that he wants to do that" (IDI \# 5, female).

Her view corroborates the perspective of one of the male respondents who stated that decision-making is his prerogative. According to him: "It is me who makes the decision. I usually go to her first, it is not her who comes to me for a relationship, so she must listen to what I tell her" (IDI \#4, male).

Conversely, respondents indicated that female partners could initiate sex without being labeled promiscuous only if a couple had been together for a long period of time and have had sex several times already. In this respect, male partners believe that their girlfriends learnt such behavior from them, which once again reflects male dominance. One of the male respondents put it this way: "If you are meeting her for the first or second time and she tries to put you in the mood for sex, then you know she has been around, she does these things to other guys. I just deny her sex totally. But if I am meeting her for, let's say the sixth time..." In respondents' statements about the circumstances in which females are able to initiate sex, it was evident that females could not control the decision-making process. This claim is substantiated by one of the female respondents, who said: "It's me who initiates it. If I do not want to have sex I 
do not want to, and I will not change my mind. But my first boyfriend was the one who influenced me to have sex. My second boyfriend, who is my current boyfriend, also used to decide when we would have sex" (IDI \#6, female).

Most respondents stated that males did not get intimidated by female sexual demands. If male partners did not want to have sex at a particular time or at a particular place, they stuck to their decisions and girlfriends were expected to respect them. "I just tell her that I am fatigued. She puts on a sad face, but I don't care about that. If I am not in the mood, I am not in the mood" said one of the male respondents (IDI \#4, male). On the other hand, for most female respondents their boyfriend's refusal to fulfill their sexual needs felt like some sort of punishment. In spite of this, they knew that they had to accept their male partner's decisions or risk being labeled whores. "As girls it is not easy to say, why don't you want it now, what happened, let's make love now. You do not want to show that you are weak. But you feel like maybe there is something you have done and he is punishing you" (IDI \#6, female). The respondents stated that some female partners are able to decide about the timing of sex if they have been in long and stable relationships characterized by openness and love. In such a setting, either of the partners would respect the other's decisions. "I understand, because he too also understands. If I am not in the mood for sex, he accepts this, and I likewise accept his feelings" said one female respondent (IDI \#4, female).

In addition, some respondents said that during their first sexual encounters with a man the female partner was more likely to influence the timing of sex than in subsequent sexual encounters. Initially, boyfriends are not assertive enough to dictate the timing of sex; if a girl is not happy with the conditions of the first sexual encounter, she may simply refuse further advances. The above-described conclusion was derived from respondents' answers. According to one of the males: "If it is her first time with you, she can leave anytime, anywhere, anyhow without having sex, but if you are familiar with each other, it is difficult for her to leave and deny you sex" (IDI \#10, male). Concerning decisions about where sex should take place, most of the respondents stated that the man is the decisionmaker. Most of them found it funny to be asked where partners should go to have sex, since it is common knowledge that the male partner decides on the venue: usually his house, or a hall of residence. "We do not argue about the venue. Because I believe that sexual intercourse should be done at a man's place, and that's how we decide it" (IDI \#6, female). 


\section{Partner Communication about sexual risks and decision- making about safe sex practices}

Regarding partner communication about condom use, the respondents contradicted themselves, at times agreeing that partners openly communicate, but later on denying this, saying that partners mainly use cues to express their desire to use condoms. This is based on the assumption that girlfriends know the meaning of such cues and respond to them accordingly. "They [girls] obviously think we both want to use condoms, so I just get condoms and let her see them. If she has a problem with them, then I know it" (IDI \#5, male).

When asked about who initiates discussions about condom use, the respondents stated that girlfriends expect and wait for boyfriends to start such discussions. They also believed that boyfriends should take precautions in order to lessen sexual risks. Girls who suggest the use of condoms or keep them risk being labelled sluts, or are dumped, as indicated by some female respondents as follows: "Normally, when you go to sleep over at your boyfriend's house you don't ask for or bring condoms; you expect him to have condoms. One of the reasons for this is that a girl fears that he will think that she is sleeping around (IDI \# 5, Female). Another female respondent corroborates this: "I don't talk about condoms. My boyfriend was older than me, he knew all about sexual intercourse. So I thought he would protect me from diseases and pregnancy" (IDI \#6, female). Similarly, the fear of being a sleep-around or flirt makes girls reluctant to suggest that their partners use condoms. "A girl fears that people will think that she is sleeping around if she picks up condoms. If you take condoms to your boyfriend, guys usually say, what do you expect, you think we are going to have sex? You feel uncomfortable" (IDI \#5, female).

As to why condom use is not freely discussed, the respondents stated that discussing condoms connotes promiscuity. Suggesting that condoms be used could destabilize a relationship by introducing an element of mistrust and suggesting promiscuous sexual practices. Most people think that condoms should be used when having casual sex. One of the male respondents said: "When I told my girlfriend about condoms, she did not want to use them because she thought that I did not trust her; she said, you do not love me (IDI \#1, male). In addition, other respondents stated that partners who introduce condoms may be suspected of being HIV positive or suspect that their partners are infected with HIV or that they do not want to have their boyfriends' children. A female respondent felt that her boyfriend would think that she suspected him of having AIDS, or that she did not want to have his child. Thus, some partners avoid condom-related discussions. 
All respondents individually acknowledged the importance of discussing HIV and pregnancy-related issues with partners. Partners who frequently communicated their fears of sexual risks were more likely to use condoms regularly. Partner communication was also viewed by other respondents as a strategy for creating awareness about the dangers associated with risky sexual practices. Both female and male respondents stated the reasons that they might use condoms. A male respondent was convinced that condom use could prevent unwanted pregnancies. According to him: "I wanted to avoid having an unplanned child or catching a disease. As I talked to her about it, she just listened. At first she did not want to use condoms, but as time went on she accepted it" (IDI \#1, male). For another respondent: "I and my girl have discussed HIV several times. If one of us gets HIV it means that both of us will be in danger. So it is our responsibility to make sure that we do not get sick" (IDI \#1, male). In addition, respondents said that couples who are in stable relationships openly communicate about sexual risks as a sign of love and honesty, even if such talk could offend their partners: "We talk about HIV because I love her and do not think I would lie to her" (IDI \#6, male).

With regard to the strategies employed to express fears about sexual risks, the respondents said that cues are used. Respondents stated that partners refer to particular people that they both know who are living with HIV/AIDS or who have died of HIV/AIDS to encourage safer sex practices. A female respondent said: "We talked about women in our location that died of HIV. We said that if we do not use condoms we will get HIV as well. The pain is not good" (IDI \#7, female). Respondents also said that partners mention the negative repercussions people face as a result of unwanted pregnancies to encourage their partners to accept the use of contraception in their relationships. "We were talking about his friend that has an unwanted baby, so I started asking him about it, and he said they decided to have an abortion. So I said to him, these are the disadvantages of not using a condom, so it's better that we use condoms every time we have sex" (IDI \#7, female).

Respondents agreed that partners draw on the media (television and radio programs) to communicate their concerns about sexual risks. Certain programs portray the agony and pain that individuals feel about having an HIV/AIDS infection. At times, the media portray the repercussions of unplanned pregnancies such as abortion. As one of the female respondents stated: "I bring up the subject of HIV and other sexual matters - when the TV or radio covers such topics, then I turn around and say, 'what about that'? 'How do you think we should avoid it'? In this manner I convey my concerns" (IDI \#5, female). Similarly, the respondents also maintained that partners introduce the topics of HIV/AIDS and unwanted pregnancies in form of asking relevant questions. This creates a 
favorable environment in which partners can discuss their own fears and behaviors concerning sexual risks. "I ask jokingly if she knows about HIV and unplanned pregnancies, and what her view is about these issues. I might say, 'I have got a friend who has an STI, so what is your view about this?'” (IDI \#2, male).

However, respondents at times contradicted themselves, saying that discussing HIV/AIDS related issues was irrelevant to them as young people because such a discussion should be for HIV+ positive people, not for those who are not ill. Some male respondents stated that: "I don't think we need to talk about HIV because the thing [the topic of AIDS] is for those people who have it" (IDI \#5, male). "We talk about nice things like romance, orgasms, etc., not HIVIAIDS; this is for those who have the virus" (IDI \# 6).

With regard to revealing one's HIV positive status, most respondents said that it is not easy to do so. However, none of the males said they would keep their HIV status a secret. For some, a HIV infection is not something one can conceal forever. For others, revealing their HIV status to their partner is important so that they can seek medical help if they are also infected. Different respondents have different, specific reasons for revealing their HIV status to their partners. One male respondent frankly stated that he would: “...let my partner know my HIV status so that she can go for HIV testing and get treatment" (IDI \#10, male). In addition, the respondents believed and stated that if the sexual partners are not infected, then the HIV positive person should reveal their status to avoid infecting their partner. "Yes, I would have to, so that I don't infect her" (IDI \#2, male). Also, other respondents would be inclined to reveal their HIV status to partners they love. Partners deserve to know each other's status so that they can make decisions about their health and the future course of their relationship. "I would tell her my HIV status because our relationship is characterized by trust. If she feels that leaving me is the right thing to do, she can leave me" (IDI \#1, male).

From all the study respondents, only a few females said they would keep their HIV status a secret for fear of hurting their partners. Also, a few female respondents felt that their HIV status is their own business and they would not have to reveal it to anybody, especially boyfriends. This position suggests a low level of honesty and openness among them vis-à-vis their male counterparts who vocally tend to be more open towards revealing their sexual health status. According to one of the female respondents: "I think I would not tell him because I would not want him to be broken; having HIV+ status is difficult to accept" (IDI \#4, female). In the words of another female: "I do not think he would pay for my medical expenses, I owe him no explanation" (IDI \#3, female). The above responses of some females indicate a strategy of deceit, dishonesty and a lack of responsibility in their relationships. 
On the other hand, some individuals, especially women, who said that they would reveal their HIV+ status stated that they would do so to avoid problems that may arise if the partner finds out at a later stage: "I would tell him my HIV status. It would eventually come out if I did not because he would start asking why I am not sleeping with him" (IDI \#6, female).

\section{Strategies used to reveal HIV positive status}

Most respondents stated that they would use cues to reveal their HIV+ status. For most females, the use of cues rather than verbal messages seemed to be driven by fear of a partners' reaction. Some claimed that after asking questions relating to HIV status and seeing their boyfriends react in a scared manner they would reveal their HIV status electronically, or by convincing boyfriends to go for couple testing so that the healthcare provider would spill the beans rather than the girlfriend directly. "If I were HIV positive I would not tell him straight away. I would ask him what would happen if he found out that I was HIV positive. If his response was scary, then I would send him an SMS" (IDI \# 5, female). Yet another female respondent said she would want to go to couple testing. According to her, "If it is HIV I would tell him that we should go and get tested together. From this, he would know our status" (IDI \# 6, female).

Conversely, most male respondents stated that they would reveal their HIV status to partners openly and freely. The thought of how their partners would react would not influence their decision to reveal their HIV status. In the words of two male respondents: "Immediately after you come out of the clinic, you phone and tell her that you went to the clinic and got tested and they found this and that condition. If she wanted to she could leave me (IDI \#7, male). "I went to a bash and got drunk and had unprotected sex and I am now infected with HIV" (IDI \# 8, male).

Some male respondents said they would use cues to reveal their HIV+ status; the partner would ask questions about HIV status to gauge whether or not their partner was ready to know. For others, convincing their girlfriends to go with them for HIV testing so that they can eventually blame them for their condition is the way to go. According to one of the respondents, "I would start by asking some questions. Like what would you do if something like this happened? I would wait to hear from her and then tell her that it is not easy" (IDI \#1, male).

"I would tell her so that she could get tested, and then I would say I got it from her because before I met her I was not sexually active" (IDI \#7, male). 
Regardless of whether communication is open or concealed, respondents indicate that most of the relationships of the young students at Walter Sisulu University are characterized by some form of sexual coercion.

\section{Sexual Coercion and coercive experiences}

The respondents reported that blackmail was a common coercive experience. They stated that some partners, especially boyfriends, blackmailed partners by doubting their commitment and love if they refused to yield to their sexual demands. For most respondents, sex made a relationship solid and stable because it connoted love and commitment. For most respondents, denial of sex was only tolerated at the beginning of an affair. As a result, some people engaged in sex against their will in order to prove their commitment to the relationship. Some male respondents echoed:

"I want to prove that I am loyal to you, so you must prove that you are loyal to me too by making love to me. If boys do not succeed in this, the relationship is not worth keeping" (IDI \#3, male).

"Eh! It pisses me off! Like these girls I have, if we already are having sex and now she does not want to, she has to provide a good reason. But with someone I have just met, I don't have a problem if she refuses to have sex" (IDI \#3, male).

"If she refuses to have sex, the guy normally gets angry, some guys attempt to beat that lady" (IDI \#2, male).

All respondents, but especially females, reported abandonment as the most common coercive experience encountered by students at the campus. Most females said that their boyfriends were at times unfaithful and when confronted about their infidelity would physically assault or abandon them. The respondents maintained that male partners dumped girlfriends who no longer excited them sexually, or girlfriends whom they could no longer control. Based on her experience, one of the female respondents said: "I experienced partner abuse, like someone hitting me because I wanted to use a condom and he did not want to; my second boyfriend did that, and he was always cheating on me. He would call me and say he was sorry, but we eventually broke up" (IDI \#6, female). The reality of the above experience is corroborated in a response by one of the male respondents: "I have got principles: if a girl does not want to play according to my principles we just break up. I must use a condom, I do not hide my other girlfriends from her - if a girl does not want this, we just breakup" (IDI \#9, male).

Most respondents stated that young women at a socio-economic disadvantage were coerced into early sexual behavior and unprotected sex by male partners 
who materially provided for them. Failure to consent meant losing out on the assistance men offered, yet for some females, such assistance was a necessity. For other girls, failure to consent to partner sexual demands ended in rape. The respondents said that in most of these sexual encounters condoms are not used. "Girls say, I want to go out, go to town, go for dinner, get cosmetics, they want their rooms to look expensive, have computers in their rooms and all these demands" (IDI \#7, female). "Some people who are party animals, they drink alcohol and the boy says you don't just drink my alcohol, you must give something in return" (IDI \#5, female).

Forced unprotected sex was also common at campus. The victims of forced sex were mainly females, and the perpetrators were mainly male strangers and colleagues or partners who paid visits to rooms for academic and non-academic purposes. For some men, if a girl visited them or welcomed them in her room, especially at night, it indicated that she wanted to engage in sex. Also, if girls dressed seductively during such visits, the likelihood of rape was high. In these scenarios, condoms are in most cases not available or are deliberately ignored.

"It's when you go to his place to visit, or he visits you in your room that he forces you to have sex without a condom" (IDI \#5, female) said one of the respondents. One of the male respondents portrays a picture of one of the contexts when rape can occur. In his words: "A guy may visit a girl in her room, this lady may want to go or come out of the bathroom with just a towel wrapped around her, this may lead to rape" (IDI \#9, male). In addition, some respondents indicated that some male partners do not want to use condoms with their girlfriends and may physically force them to engage in unprotected sex. In this setting, condoms are again in most cases not available, or are deliberately ignored. According to one of the respondents: "The point is, when he does not want to use condoms I cannot do anything about it. He forces me" (IDI \#5, female).

Most respondents did not condone forced sex. Some respondents claim that there are many women willing to consent to sex, thus there is no need for rape. However, for a few of the respondents, forced sex was justifiable, especially if a woman tried to dodge having sex with a man who had given her money or gifts. Some male respondents stated:

"There are so many women who would willingly have sex, there is no need for rape” (IDI \#4, male).

"I saw my friend getting arrested for rape. I would never do that" (IDI \#3 male).

"I do not think a guy feels good if a lady is given money, clothes and other things, but when the guy wants to sleep with her she disagrees" (IDI \#8, male). 


\section{DISCUSSION OF FINDINGS}

Even though literature informs us that communicating with a partner is an important part of self-protective health behavior, the current study findings suggest that free and open partner communication about sexual matters was limited among young students. The form of communication preferred was the use of cues, which at times would be misunderstood. Actions such as kissing, touching, undressing, honoring appointments or avoiding them were used to indicate acceptance of the other partners' sexual advances or refusals to yield to sexual demands. Similar findings have been documented by Khan (2001) in a study conducted in Bangladesh. Khan (2001) found that physical touch (pushing, pulling or touching the husband's body) was used by women to express their sexual desire. In the same vein, the current study showed that partners used cues to convey their desire to use condoms. Male partners would store condoms in places where girlfriends could easily see them, or told girlfriends to pick up condoms as a cues for their intention to use condoms. This was based on the assumption that the cues would be clearly understood. Similarly, the partners used cues to communicate messages about HIV/AIDS and the prevention of unwanted pregnancies. Horrible events or stories highlighted by the media outside the couple's own relationship were referred to; participants also said that partners referred to HIV positive people and pregnant teenagers they both knew who were in a bad situation. This concurs with study findings from Malawi. In Malawi, Zulu et al. (2002) noted that in order to avoid conflict, discussions about HIV/AIDS risk and preventive strategies were often introduced with reference to stories and events related to AIDS and irresponsible sexual behaviors outside the immediate domestic sphere.

Participants said that partners preferred to use cues because free and open communication about sexual issues was uncomfortable since it antagonized people, and that partners viewed this type of communication about sexual desires as shameful, with its connotations of promiscuity, disrespect and lack of trust. However, the irony of using cues to show one's desire to have sex, to use condoms and to portray sexual risks as horrors to convey preventive messages was that they were at times misinterpreted or misunderstood. For instance, for some, especially females, kissing and touching did not necessarily mean saying yes to sexual intercourse, yet for most males it meant this. Issues such as these elevated the likelihood of nonconsensual and risky sex encounters.

Inferring from the current study findings, the existence of predefined cultural norms that create different standards for each gender were evident. Young men dominated decision making: they initiated sexual intercourse, they determined the timing of the sexual act and the conditions under which it occurred. Male 
domination was generally seen as acceptable to both genders; female partners respected and obeyed male decisions, not vice-versa. Similar findings were documented by Gage (1998) who revealed that $59 \%$ of university students of Freetown in Sierra Leone believed that it was the man's responsibility to bring up issues of safe sex. Also, in a study carried out in Swaziland, both adolescent boys and girls believed that boys had a 'natural right' to make more demands in sexual relationships (Gage 1998). The present study, however, indicated that some females could influence sexual decisions if they had been in a relationship for a long period of time, and that this was possible only if the boyfriend confidently believed that they had learnt this behavior from them In addition, when the sexual relationship was beginning, some women reported being able to exert more influence over sexual issues; a form of behavior only tolerated by boyfriends who were driven by the fear that if they tried to dominate the relationship the affair might end before it even began. In circumstances where partners' views clashed over sexual issues, females were reportedly coerced into a state of powerlessness.

Furthermore, inferring from the participants' views, the study found that communicating one's HIV status to partners if found to be HIV positive was not easy. Nevertheless, keeping one's HIV positive status a secret was not an option for the majority of the respondents. This suggests that awareness-campaigns promoting partner communication about HIV/AIDS testing and the need to reveal one's status to loved ones is to a certain extent yielding success. However, the reasons that young people claimed they would reveal their status show the existence of a power imbalance - a factor that adversely affects health practices. For most young women, the urgency of revealing their status earlier to partners was driven by the fear of the wrath of male partners who would find out the truth later. Similarly, the strategies young women use to reveal their HIV status show power dynamics at play. Some young women said that they would send a text message to avoid the partner violence which might occur if the message was conveyed face-to-face; alternatively, they would convince boyfriends to visit a clinic so that healthcare workers could reveal the findings to both partners. This way their boyfriends might not be sure of who infected who, and hence be less violent. Yet again, this action suggests power dynamics. Women fear the wrath which might be incurred by openly and freely revealing their HIV+ status to boyfriends. This finding also suggests that there is ignorance about the importance of HIV counselling among university students.

Conversely, most of the young men's responses about revealing their HIV status and the strategy they employed to do so showed that young men were less concerned about whether or not (and to what degree) such scary news would impact partners. The following themes emerged from their responses: "I tell 
them I'm HIV+ and get it off my chest", "I have to get her tested and blame her for infecting us". This again suggests that men indirectly influence decision making about how HIV+ status should be revealed.

\section{Factors that inhibit or facilitate shared-decision making about the practice of safe sex}

This study revealed that the gender-specific responsibility that was assumed to a large extent created a barrier to discussing condom use. Most of the participants believed that it was the responsibility of the male partner to raise the issue of condom use. Some participants, especially females, assumed that their partners knew what to do because they were sexually aware and experienced. Hence it was not necessary for girls to suggest the use of condoms. All the participants believed that it was men who were responsible for taking precautions. Women are expected to listen and obey. Therefore, women waited for male partners to initiate such discussions. In Thailand, Gage (1998) documented similar findings about condom use being considered the male prerogative. Also in Thailand and Guatemala, female ignorance of sexual matters was often viewed as a sign of purity and innocence, while having 'too much' knowledge about sex was a sign of 'easy virtue' (Rivers and Aggleton 1998). In the current study, relying on male partners to initiate and decide about condom use, and moreover, using cues to communicate intentions which were at times misunderstood, was inadequate. Consequently, it was likely that partners would not use condoms or only inconsistently use them.

In addition, verbally introducing the issue of condom use in a sexual relationship connoted promiscuity and generated antagonism in relationships. In stable partnerships, discussing condoms introduced an element of distrust since condoms were associated with promiscuity or/and the suspicion that a partner might be HIV positive. Similarly, in a study conducted about condom use and sexual behaviors in Southern Africa, condoms were often viewed as necessary only for those infected with HIV or STDs (Varga 2003). Given this perception, individuals in most relationships, especially those considered stable, failed to discuss and later on use condoms. Similarly, in the current study initiating free, open discussion about HIV/AIDS and pregnancy suggested that a partner was violating the trust, commitment and intimacy of the relationship. In addition, for some participants talking about HIV/AIDS was not a necessity because such talk is deemed only for people already infected with HIV. Partners instead used cues to communicate about sexual risks, although these cues would at times be misunderstood. Thus the importance of the self-protective behavior that open communication and shared-decision-making can produce was downplayed. 


\section{Sexual coercion}

In their study in Kwazulu-Natal, Maharaj et al. (2007) observed that sexual coercion was a major barrier to the adoption of safer sexual behavior. Similarly, in the current study, partner abandonment was a common form of coercion within relationships. For male partners, girlfriends who were no longer sexually exciting, who refused to yield to partners' sexual demands deserved to be dumped. For most young men, sexual activity is a sign of manhood, condom use is a barrier to enjoyable sex, and having many girlfriends means earning peer respect. Thus the fear of being abandoned forced young women to submit to the sexual demands of their lovers, regardless of the sexual risks it involved. Similarly, in Kenya Longfield et al. (2002) documented that in cross-generational relationships, older men "dumped" young partners once their sexual needs were satisfied. Conversely, the current study found that young women abandoned partners who were unfaithful or physically or emotionally abusive or financially unable to support them. However, boyfriends did not seem to be greatly affected by such abandonment. This is reflected in their statements that "there are many fishes in the sea", which literally means that there are plenty of girls to have sex with. Similarly, in Kenya, Longfield et al. (2002) documented that some young women dumped older partners who were cheats and upon whom they could no longer emotionally and financially depend for new partners.

The current study found that forced sex was another form of coercion employed by young people. Sometimes men visited female rooms or invited girls to male (single-sex) rooms and forced them into unprotected sex, or raped them as they walked home alone at night. The distressing fact was that the perpetrators were mainly stable sexual partners and colleagues or friends the victims were familiar with. Similarly, in Kenya Idele-Akwara (2002) noted that intercourse occurred in a place determined by the man; in most cases his house or a friend's house or an isolated field or place. The woman often ended up agreeing to have sex even if this was not on her mind in the first place. Finally, the current study revealed that women who accepted material goods from men and then tried to 'dodge' men's sexual demands were coerced into sex. In this scenario, perpetrators were mainly acquaintances and in a few instances, strangers. A study in a South Africa township found that rape was routine, and $60 \%$ of young African women had been forced to have sex against their wishes (Hallman 2004). In the current study, although rape was not condoned, participants felt that girls who accepted material objects from men and tried to dodge their sexual demands deserved to be raped. 


\section{CONCLUSION}

The current study found that free and open verbal discussion about sexual intercourse, condom use and HIV/AIDS-related issues was rare as it was believed to antagonize relationships. Such discussions generated suspicions of HIV infection, infidelity and a lack of trust. This downplays the importance of selfprotective health behavior that free and open partner communication, as well as shared-decision making, can create. The current study found that partners would rather engage in risky sexual practices than risk riling their sexual partners through verbal discussions about safe sex practices. Studies indicate that this indirect strategy of partner communication and the use of cues is at times flawed through misinterpretation and misunderstanding. Similarly, the current study found that partners preferred using cues to communicate their perceptions, desires and concerns about sexual intercourse, safe sex practices and sexual risks. It was observed that some participants would misinterpret or misunderstand cues used by their sexual partners. Owing to this fact, partners' reproductive health choices were likely to be compromised, especially when non-verbal disagreements and misunderstandings between men and women arose. Literature has shown that gender differences bolstered by gender-specific communication obstruct partner negotiation and lead to miscommunication and misunderstanding. The current study found that male domination in communication and decision-making about sexual intercourse and safe sex practices was considered obvious and generally acceptable. Different cultural expectations and standards seemed to support greater precedence being given to the sexual needs of men. Most female partners preferred to yield to the desires of their male friends than risk partner coercion in the form of abandonment, blackmail or forced unprotected sexual intercourse. This behavior compromised the reproductive health choices of university students. In light of this, the following recommendations are proposed: Given that young men have to prove their masculinity, which is associated with domination, and women have to prove their femininity, which is associated with passivity and obedience, there is an urgent need to redefine the cultural norms that define the different standards for each gender. Thus, health-promoting messages that incorporate the contexts in which free and open partner communication and shared reproductive decision-making take place need to be encouraged, especially since the study found that verbal communication was limited.

Partner coercion need to be addressed since it encourages male dominance over females and discourages shared decision-making about engaging in safer sex practices. Furthermore, studies have shown that the ability to negotiate safer sex behavior is dependent on shared decision-making about how to prevent sexual risk-taking behavior. Given the importance of this, the reproductive health 
precautions promoted within campus need to go beyond prevention messages and incorporate safe sex negotiation skills.

One of the limitations of this study, however, is its small sample size. In addition, the results cannot be generalized since the study was contextual in nature; interviews were personally conducted amongst individual students at one single university in South Africa (Walter Sisulu University).

\section{REFERENCES}

Agadjanian, V. (2002), “Men's talk about “women's matters": Gender, Communication and Contraception in urban Mozambique", Gender and Society Vol. 16, No 2, pp. 994-215. doi: 10.1177/08912430222104903

Blanc, A.K. (2001), "The effect of power in sexual relationships on Sexual and Reproductive Health: an examination of the evidence", Studies in Family Planning Vol. 32, No 3. pp. 189-213. doi: 10.1111/j.1728-4465.2001.00189.x

Conroy, A., A. (2014), "Gender, Power, and Intimate Partner Violence: A Study on Couples From Rural Malawi”, Journal of interpersonal violence Vol. 29, No 5, pp. 866-888. doi: 10.1177/0886260513505907

Gage, J.A. (1998), "Sexual Activity and Contraceptive Use: The components of the decision-making Process", Studies in Family Planning Vol. 29, No 2, pp. 154-166. doi: $10.2307 / 172156$

Hallman, K. (2004), "Socio-economic disadvantage and unsafe sexual behaviors among young women and men in South Africa", Policy Research Division Working papers No. 19. New York, Population Council, www.popcouncil.org/ publications/wp/prd/rdwplist.html.

Idele-Akwara, P.A. (2002), The social context of perception of AIDS risk and Sexual behavior in Kenya: the truth about AIDS. http://www.socstats.soton. ac.uk/choices/Aids Risk Kenya.

Jejeebhoy, J.S. (2006), Sexual and Reproductive Health of young people: Expanding the Research and Program Agenda. New Delhi, Population Council Kaufman, C.E. - De Wet, T. - Stadler, J. (2001), "Adolescent pregnancy and Parenthood in South Africa", Studies in Family Planning Vol. 32. No 2, pp. 147-160.

Khan, M.E. (2001), Peeping Behind the Closed Door: A qualitative Study of Sexual- behavior of Married Women in Bangladesh. Population Council, Dhaka, Bangladesh [http://www.iussp.org] 
Longfield, K. - Glick, A. - Waithaka, M. - Berman, J. (2002), “Cross-generational relationships in Kenya: Couples' Motivations, Risk perception for STIs/HIV and Condom Use", Population Services International (PSI) Research Division. Working paper No. 52.

Maharaj, P. (2001), "Male attitudes to Family Planning in the Era of HIV/AIDS: Evidence from Kwazulu-Natal, South Africa", Journal of Southern African Studies Vol.27,No2,pp.245-257.http://dx.doi.org/10.1080/03057070120049958 Maharaj, P. (2001), "Obstacles to Negotiating Dual Protection: Perspectives of Men and Women", African Journal of Reproductive Health Vol. 5, No 3, pp. 150-161. doi: 10.2307/3583332

Maharaj, P. - Munthree, C. (2007), "Coerced first sexual intercourse and selected reproductive health outcomes among young women in KwaZulu-Natal, South Africa", Journal of Biosocial Science Vol. 39, No 2, pp. 231-244. doi: 10.1017/ S0021932006001325

Mesce, D. - Sines, E. (2006) Unsafe abortion: Facts and Figures. Population Reference Bureau. http://www.prb.org.

Minnis, M. A. - Doherty, A. I. - Kline, L. T. - Zule, A. W. - Myers, B. - Tara Carney - Wechsberg, M. W. (2015), "Relationship power, communication, and violence among couples: results of a cluster-randomized HIV prevention study in a South African township" International Journal, Women's Health vol. 7, pp. 517-525. [www.ncbi.nlm.nih.gov/pmc/articles] doi: 10.2147/IJWH.S77398

Nugent, R. (2005), Youth in a Global World. Population Reference Bureau (PRB) http://www.prb.org.

Nu Tanga - Lisamarie Bensmana - Elaine Hatfield (2013), "Culture and Sexual Self-Disclosure in Intimate Relationships" An International Journal on Personal Relationships: Interpersonal Vol. 7, No 2, pp. 227-245. http://www. elainehatfield.com/uploads.

Parker, W. (2003), "Re-appraising Youth prevention in SA: The Case of Love Life", Paper presented at the South African AIDS Conference. Durban, South Africa.

Pembrey, G. (2006), Averting HIV and AIDS. http://www.avert.org/ aidssouthafrica.

Population Reference Bureau (2013), The World's Youth 2013 Data sheet: Health risks and Behaviors.

Rivers, K. - Aggleton, P. (1998), HIV and Development Programme: Adolescent Sexuality, Gender and the HIV Epidemic. http://www.undp.org/hiv/ publications/gender/adolesce.

Sines, E. - Tinker, A. - Ruben, J. (2006), The Maternal-New born - Child Health Continuum of Care: A Collective Effort to Save Lives, Population Reference Bureau, Washington, DC. 
South African Demographic and Health Survey (SADHS) (1999)

South African Demographic and Health Survey (1998), Full Report. South African Medical Research Council and Measure DHS, Pretoria.

Swartz, L. (2003), Fertility Transition in South Africa and its impact on the four major population groups. http://www.hsrcpress.ac.za

Tamaryn L. - Lynn T. - Janet Giddy - Norma C. - Jennifer A. - David R. Bangsberg (2013) "A conceptual framework for understanding HIV risk behavior in the context of supporting fertility goals among HIV-serodiscordant couples" Reproductive Health Matters Vol. 20, No 39, pp. 50-60. doi: 10.1016/ S0968-8080(12)39639-0

UNAIDS (2004) Report on the Global AIDS pandemic. Geneva, Joint United Nations Programme on HIV/AIDS

UNFPA South Africa Factsheet (2013) Young people. (http://www.countryoffice. unfpa.org/southafrica/young_people)

United Nations Department of Economic and Social Affairs (2015) Population Facts, Population Division. No 2015/1. www.unpopulation.org

Varga, A.C. (2003), "How Gender Roles Influence Sexual and Reproductive Health Among South African Adolescents", Studies in Family Planning Vol. 34, No 3, pp. 160-172. doi: 10.1111/j.1728-4465.2003.00160.x

WHO (2005), Selected practice recommendations for contraceptive use, Geneva, WHO

Zulu, M.E. - Chepngeno, G. (2002) Spousal communication about Risk of contracting HIVIAIDS in rural Malawi. Max Planck Institute for Demographic Research. http://www.demographic-research.org 